\title{
ACUTE DISSEMINATED (SEPTICÆMIC) MONILIASIS IN ADULTS AND CHILDREN
}

\author{
Rosalinde Hurley, M.D., M.C.Path. \\ Department of Bacteriology, Queen Charlotte's Maternity Hospital, London, W.6, \\ and the Institute of Obstetrics and Gynaecology.
}

IN 1846 Berg established that the fungus now known as Candida albicans was the cause of thrush. The first intimation that it might be other than a purely superficial pathogen was probably the demonstration by Virchow (18211902) of fungal elements penetrating the submucous layer of the oesophagus (Plaut and Grutz, 1927); in 1861 Zenker described metastasis to the brain, commenting that the infection was probably bloodborne from the thrush lesions of the tongue and gullet. Thereafter reports of systemic spread to the viscera demonstrated at necropsy occurred sporadically (Wagner, 1868; Heller, 1899). Joachim and Polayes (1940) cultured a yeast-like fungus, subsequently identified as $C$. parakrusei (Polayes and Emmons, 1941), from the bloodstream of a living patient who succumbed to endocarditis and in 1945 Wessler and Browne reported isolation of $C$. albicans from the bloodstream of a patient who recovered from the infection.

The experimental disease has been studied extensively and it is agreed that $C$. albicans is pathogenic for all common laboratory animals when injected by the intravenous route. For some years, following Benham (1931), C. albicans was regarded as the only member of the genus of proven pathogenicity and statements to this effect appear in standard textbooks (Dubos, 1958). This view has been challenged and there is evidence that other commensal species of Candida are pathogenic (Mackinnon, 1936; Meyer and Ordal, 1946; Mankowski, 1957; Hasenclever and Mitchell, 1961; Hurley, 1962; Hurley and Winner, 1962). These species have been isolated from monilial lesions in the human and their status with respect to human disease, particularly the disseminated type, should be reassessed, since it is dangerous to regard them as contaminants (Richart and Dammin, 1960). Experimentally, all pathogenic members of the genus result in disease indistinguishable from that caused by C. albicans.

It is the purpose of this paper to review the pathology, the main clinical features, the prognosis and the treatment of acute disseminated ${ }^{\circ}$ moniliasis, and to describe three further cases.

\section{Review of Previous Reported Cases}

Previous reviews of acute disseminated (sep- $\vec{z}$ ticæmic) moniliasis in adults are those of Braude and Rock (1959) and Louria (1962) (see also Winner and Hurley, 1964). For pư poses of the present review, disseminater mycotic disease caused by any member of the Candida genus is included and culture of these fungi from the bloodstream during life in the presence of demonstrable disease, or their de-s monstration in lesions in the tissues after death, are taken as diagnostic criteria. While it is admitted that positive blood cultures may be $\stackrel{\square}{\perp}$ evidence of some other manifestation of $\overrightarrow{\vec{A}}$ Candida infection, for example, of endocarditis $\frac{3}{3}$ or pyelonephritis, it is felt that in most well- $\bar{P}$ documented cases the clinical picture should serve to distinguish such cases. The former 0 syndrome has been well reviewed by Pearl and Sidransky (1960) and by Andriole, Kravetz, Roberts and Utz (1962), while in the latter there is disease confined to the renalo tract (Hurley, 1962). Cases occurring in childhood and complying with the criteria stated above are also reviewed. The cases are sum- $\rightarrow$ marised in Tables 1 and 2 .

Of the sixteen cases occurring in childhood, $\tilde{N}$ C. albicans was cultured from the bloodstream during life, the necropsy lesions, or both in $\mathcal{N}$ thirteen cases. In one case $C$. tropicalis was $\omega$ cultured from the blood, cerebrospinal fluid and urine; in another $C$. pseudotropicalis wase cultured from the blood. In another, an un- $\mathbb{\Phi}$ identified species of the genus Candida was cultured from the bloodstream during life. 
TABLE $1^{*}$

\section{Disseminated Moniliasis in ChildhoOd}

\section{Authors \& Date}

Bendel \& Race,

Chapman,

Duhig \& Mead,

Duhig \& Mead,

Duhig \& Mead,

Gausewitz et al.

Lelong et al.

Robertson,

Vince,

Vince,

Vince,

Vince,

Vince,

Vince,

Walz et al.
Sex \& Age

1961 F. 5 years

1957 F. 13 months

1951 M. 14 months

1951 M. 11 months

1951 M. 7 months

1951 M. 5 months

1951 M. 10 years

1953 M. 1 month

1956 M. 2 years

1959 F. 18 months

1959 F. 6 months

1959 F. 1 year

1959 F. 18 months

1959 M. 8 months

1959 F. 5 months

1956 M. 4 years
Associated Disease

Aplastic anæmia

Hæmophilus-meningitis

Salmonellosis

Gastro-enteritis; Mastoidectomy

Salmonellosis; Mastoidectomy

Salmonellosis; Mastoidectomy

Debility; ? lupus erythematosus

Otitis media

Hæmophilus-meningitis

URT infection; Pneumonia;

Urinary infection

Pneumonia

Cleft palate; Pneumonia

Hydrocephalus

Otitis media

Pneumonia

Lipoid nephrosis
Infecting Organism Result

C. albicans

C. albicans

C. albicans

C. albicans

C. albicans

C. albicans

C. albicans

C. albicans

C. albicans

C. albicans

Unidentified

C. albicans

C. tropicalis

C. pseudo-tropicalis

C. albicans

C. albicans
Death

Death

Death

Death

Death

Death

Death

Death

Recovery

Improved

Improved

Death

Improved

Improved

Improved

Death

*From Winner and Hurley, 1964

Nine cases occurred in male and seven in female children. In no case did the disease arise in a previously healthy child, and the antecedent illnesses are shown in Table 1. In most cases there was preceding bacterial disease. In all instances, save one (Duhig and Mead, 1951), the child had been treated with at least one antibiotic, usually with several. Intravenous therapy had been given in seven cases and was regarded by Duhig and Mead (1951) as the common factor in their series of four cases. These authors considered the intravenous route to be the mode of entry of the fungi into the bloodstream, a consideration strengthened by the many reports of fungal endocarditis in main-line drug addicts (Pearl and Sidransky, 1960).

In seven cases a rise in temperature was recorded as the initial symptom of the disorder, and in others the child was probably already febrile (Robertson, 1956; Chapman, 1957; Vince, 1959). In three cases oral thrush is recorded. Skin ulcers were reported by Gausewitz, Jones and Worley (1951) and septic thrombosis at the site of the indwelling catheters by Duhig and Mead (1951).

Ten of the sixteen cases had a fatal termination, four of these having been treated for the fungus infection (Gausewitz and others, 1951; Walz, Hasenclever and McKee, 1956; Vince, case three, 1959; Bendel and Race, 1962). Six children recovered. One was treated by withdrawal of antibiotics, potassium iodide and surgical drainage of a subcutaneous abscess (Robertson, 1956). Of the five recoveries recorded by Vince (1959), one had been treated with paraoxybenzoic acid ester alone, two had this drug combined with gamma globulin, a fourth had had gamma globulin alone and a fifth had symptomatic treatment only. The mortality rate is lower than that of the adult syndrome reviewed below, so it may be possible to have transient Candida fungæmia in childhood, without organ damage.

Of the 32 cases occurring in adults $C$. albicans was cultured either before or after death, or both, in 24. In four cases the infecting funguse was identified as $C$. tropicalis, in three it was? $C$. pseudotropicalis and in the remaining case an unidentified species of Candida was cultured from the bloodstream during life and from the necropsy tissues.

Males were affected in 15 cases and females in 17. In all cases, as in those occurring in childhood, there was a history of antecedent disease, although in two of these (Parillo, 1950; Ffrench and Shenoi, 1954) the exact nature of the underlying disease is obscure. In 17 cases moniliasis occurred after operation; in three cases it followed extraction of wisdom teeth (Wegmann, 1954; Beuthe, 1955; Skobel, Jorke and Schabinski, 1955); in two cases (Richet, Drouhet, Ducrot and Jungers, 1959; Stein, 1959) it complicated cholecystectomy; in one it occurred after laparotomy for the relief of obstruction (Conn, Crean, MacCabe and MacLean, 1959); in another after duodenal fistula and subphrenic abscess; it complicated pelvic surgery (Louria and Dineen, 1960; Lehner, 1964), abdominal surgery for regional ileitis (Louria and Dineen, 1960), portal caval anastomosis (Matthias and Rees, 1956), resection of the ileum (Braude and Rock, 1959), pyelotomy for calculus (Richart and Dammin, 1960), 
TABLE 2*

Disseminated Moniliasis in Adults

Authors \& Date

Barrett et al. 1957

Beuthe,

1955

Boyd \& Chappell, 1961

Braude \& Rock,

Brown et al.,

1959

1953

(Stein

Brown et al.,

Conn et al.,

(Stein

Connett,

Dupre et al.,

Ffrench \& Sh

Higuchi and

Iwasaki,

Lannigan \&

Meynell,

Lehner,

Lehner,

Lewin,

1959)

1953 F. 63 years

1959

1959) F. 61 years

1960 F. 68 years

1962

1954

1958

1958

1959

1964

1964

1963

Lewin,

Levy \& Cohen,

Louria \& Dineen,

Louria \& Dineen,

Matthias \& Rees,

Parillo,

Richart \&

Dammin,

Richart \&

Dammin,

Richet et al.,

Schaberg et al.,

Skobel et al.,

Stein,

F. 61 years

M. 33 years

M. 30 years

M. 22 years

M. 22 years

F. 41 years

F. 68 years

M. 60 years

(Brown et al.,

Stein,

(Brown et al.,

Stein,

(Brown et al.,

Van Buren,

Wegmann,
1963

1955

1960

1960

1956

1950

1960

M. 68 years

F. 24 years

F. 39 years

M. 26 years

F. 37 years

M. 27 years

F. 65 years

1960

57 years

1959 F. 50 years

1959 F. 22 years

1959 F.

1959 M. 50 years

1953)

1959 M. 54 years

1953)

1959 M. 64 years

1953)

1958 F. 53 years

1954 M. 22 years

\section{Associated Disease}

Pancreatitis

Acute respiratory infection;

tooth extraction

Rheumatic fever; Steroid therapy

Ileum resection

Pulmonary tuberculosis

Phlebitis

Gastrectomy; Urinary infec-

tion

Fractures, colostomy, cystostomy

Anuria

Animal bite

Leukæmia

Leukæmia

\section{Leukæmia}

Pelvic surgery

Cystectomy

Carcinoma; Carotid catheterisation

Carcinoma; Carotid catheterisation

Leukæmia

Pelvic surgery

Regional ileitis

Arsenical cirrhosis, etc.

Abdominal pain

Pneumococcal-meningitis, etc.

Pyelotomy

Cholecystectomy; anuria

Poliomyelitis

Pneumonia; tooth extraction

Respiratory infection duodenal perforation

Duodenal ulcer
Biliary fistula
Myelomatosis
Agranulocytosis; tooth extrac-
tion.

$\quad$ Organism
C. albicans
C. pseudo-tropicalis
C. albicans
C. albicans
C. albicans

Result

Death

Death

Death

Death

Death

Unidentified Death

C. tropicalis

Death

Death

Death

Death

Death

Death

Death

Death

Death

Recovery

Recovery

Death

Recovery

Recovery

Death

Death

Death

C. tropicalis

C. tropicalis

C. albicans

C. albicans

C. pseudo-tropicalis

C. albicans

Death

?

Death

Death

Death

C. albicans

Death

C. tropicalis

Death

C. albicans

C. pseudo-tropicalis

Death

Death

*After Winner and Hurley, 1964.

and compound fractures with transverse loop colostomy and suprapubic cytostomy (Connett, 1960), two cases of carcinoma of the mouth and carotid catheterisation, (Lewin, 1963) and cystectomy (Lehner, 1964). In other cases reported by Brown, Propp, Guest, Beebe and Early (1953) and by Stein (1959) there was traumatic perforation of the duodenum. In seven cases moniliasis complicated the course of blood dyscrasias; aleukæmic leukæmia (Levy and Cohen, 1955; Higuchi and Iwasaki, 1958 (two cases); Lannigan and Meynell, 1959); probable hæmochromatosis and maturation arrest aplastic anæmia (Ffrench and Shenoi, 1954); multiple myelomatosis (Van Buren, 1958) and agranulocytosis (Boyd and Chappell, $\frac{D}{0}$ 1961). The antecedent diseases in the rest of the cases are shown in Table 2 .

In all cases, with the exception of Lewin (1963, case 2) and the possible exception of Parillo (1950) the patients had received multi- $\omega$ ple antibiotics. Further, 12 patients had been treated with steroids, and in 13 cases intravenous or intra-arterial therapy had definitely 0 been given. This again suggests a possible portai of entry for the Candida. 
In 29 of the 32 cases, fever is recorded as an initial symptom of the onset of moniliasis as a complication. It is sometimes described as hectic and remittent (Boyd and Chappell, 1961). Oral thrush is described in eight cases, ulceration of the mouth and gums in three, and dermatitis in two. Cerebral symptoms and signs are recorded in eight cases. Other diverse symptoms are described, but it is difficult to be sure whether these relate to the septicæmia or to the underlying disease.

Relating the presenting symptoms and signs to the necropsy findings both with respect to Candida lesions and to the primary pathology, the following symptoms or sets of symptoms appear to attend the onset of acute disseminated (septicæmic) moniliasis in adults and children; fever, with the symptoms of constitutional disturbance, malaise and anorexia; oral thrush or dermatitis and a state of diminished response to external stimuli, the condition summarised by Braude and Rock (1959) as "depressed sensorium". Other symptoms and signs depend on the site of metastasis of the fungus, or on the underlying primary pathology.

Twenty-seven adult cases resulted in death, while the outcome in one (Richet and others, 1959 ) is uncertain. Many patients had received no treatment of any sort for the fungal disease, while others had been treated in a variety of ways, ranging from the local application of gentian violet to the lesions of oral thrush, through the use of stilbamidines, nystatin and amphotericin B. Of the patients with bloodstream infections clinically acceptable as cases of acute disseminated (septicæmic) moniliasis from the history of underlying disease and multiple therapy, the only ones to recover are those reported by Louria and Dineen (1960) and Lewin (1963); these were treated with amphotericin B.

\section{Pathology}

Most of the adult cases reviewed above came to necropsy. The general picture was that of an acute, severe, widespread mycotic infection. The organ most frequently affected was the kidney, which showed multiple mycotic foci, in many cases large enough to be seen with the naked eye.

Histologically, in most cases these lesions were confined to the cortex, but, in some, proliferating fungi could be seen in the medulla. In some instances there was marked polymorphonuclear reaction to the fungus and the lesions were mycotic abscesses; in others cellular reaction was scant or absent. Budding yeasts and mycelium were demonstrated in the lesions, usually by special staining techniques. In about half the cases, there were similar lesions in the heart, and in about one third there were ulcerating lesions of the alimentary tract. Also in about one third of the cases, there were multiple mycotic foci scattered throughout the brain. Sometimes these consisted of fungi mainly in the yeastlike phase, surrounded by a zone of cerebral histiocytes; in other cases the mycelial phase of the fungus proliferated freely. The liver, the lungs, the blood vessels, the spleen and the thyroid were all involved in several cases in this order of frequency. Lesions of the bone marrow, the retina, the muscles and the bladder were each recorded in one instance.

The portal of entry of the fungus may well be the intravenous, where therapy has been given by this route. In other cases, it seems likely that it invades from the alimentary tract, where it is often present as a commensal. Mycotic ulcers of the gut may be small and may be overlooked at necropsy unless carefully sought (Ludlam and Henderson, 1942). This may account for the apparently low incidence of alimentary tract mycotic lesions in the cases reviewed above.

The cause of death is renal failure when the kidneys are heavily infected, as they usually are (Sabesin, 1962).

\section{Case Reports}

Case 1.

A woman aged sixty-two was admitted to hospital for investigation of anæmia and examination of the sternal marrow showed severe hypoplasia. Fifteen years previously she had had a left radical mastectomy for carcinoma of the breast followed by deep X-irradiation therapy and courses of testosterone and stilboestrol. She was transfused with whole blood on two occasions and discharged.

She developed perineal boils from which hæmolytic streptococci and Staphylococcus aureus were grown. She was readmitted, drowsy and semicomatose with multiple boils and spots all over the body. Her temperature was $103^{\circ} \mathrm{F}$. Hæmolytic streptococci were recovered from the septic spots and from blood cultures. She was transfused again, and given electrolyte therapy, penicillin, streptomycin and steroids. Fœtal liver cells were given intravenously and fœtal marrow was also given. Three days after the last transfusion she died.

Necropsy. There was evidence of septicæmia, aplastic anæmia, a left mastectomy scar and secondary deposits in bone. The mouth, nasopharynx and œsophagus were lined by a rough, friable brown exudate. The lining of the stomach was covered by raised circular grey brown patches up to $1 \mathrm{~cm}$. in diameter. Similar but smaller plaques were present on the peritoneal and the cut surface of the liver and similar lesions were seen on the cut surfaces of the heart and the kidneys where, however, the 


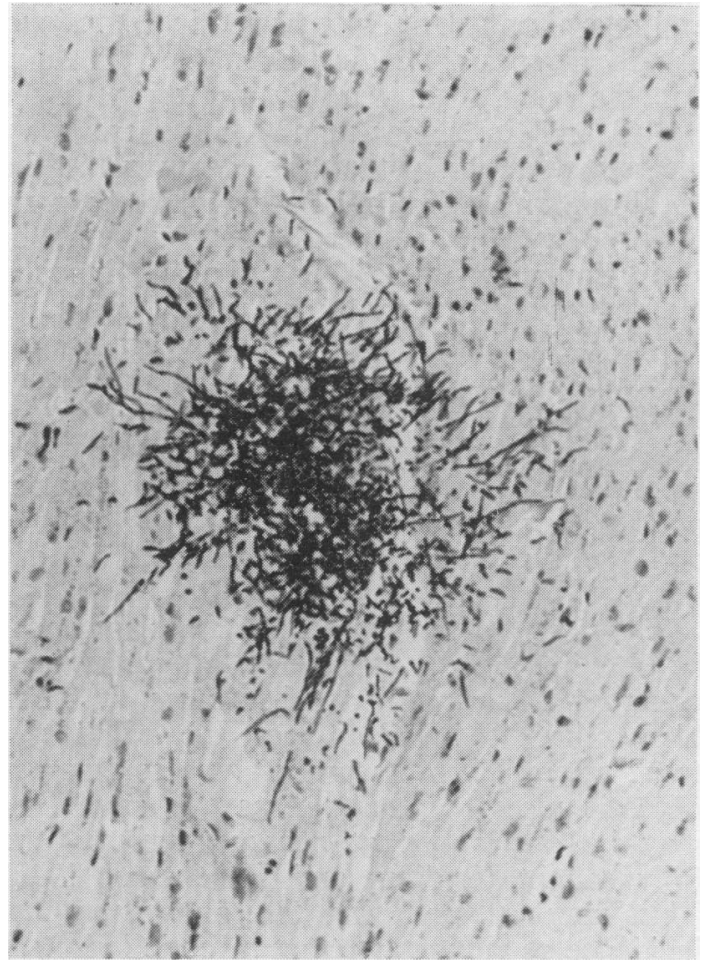

FIG. 1.-Case 1. Area of fungal proliferation in the myocardium. There is little tissue reaction. (Hurley, 1962).

P.A.S.H. x 162

periphery of the grey plaques was red. The left main bronchus and its branches were occluded by a laminated thrombus.

Histological examination showed ulcers of the œsophagus, the stomach, and the cæcum which were heavily infiltrated by a dimorphic fungus, the yeastlike form tending to be superficial, while mycelium invaded the gut wall deep to the muscularis mucosæ. A zone of inflammatory cells, plasma cells, histiocytes and lymphocytes lay deep to the invading fungus. Cellular reaction was most marked in the stomach. The heart showed multiple mycotic lesions in the myocardium of the left ventricle, the right ventricle and the interventricular septum. There was no reaction to the fungus, nor was there apparent destruction of the myocardial fibres (Fig. 1). Multiple mycotic lesions were present in the liver, unaccompanied by cellular reaction (Fig. 2); these were in the main periportal, though some were midzonal. Scattered colonies of fungi were seen in the spleen, but did not invade splenic trabeculæ. Multiple mycotic lesions were present in the kidney, these being more numerous in the cortex, and, in the main, paraglomerular, though some lay immediately subjacent to the capsule. They were of two types, the one accompanied by a border of congestion and plasma cells, the other unaccompanied by cellular reaction (Fig. 3). Both yeast and mycelium were present and there were occasional large yeast cells, about 12 to $14 \mu$ in diameter. Hyaline casts and yeasts were present in the renal tubules. The lung showed hæmorrhage and collections of yeast cells and hyphæ without inflammatory response. No fungi were seen in the bronchi or vessels.

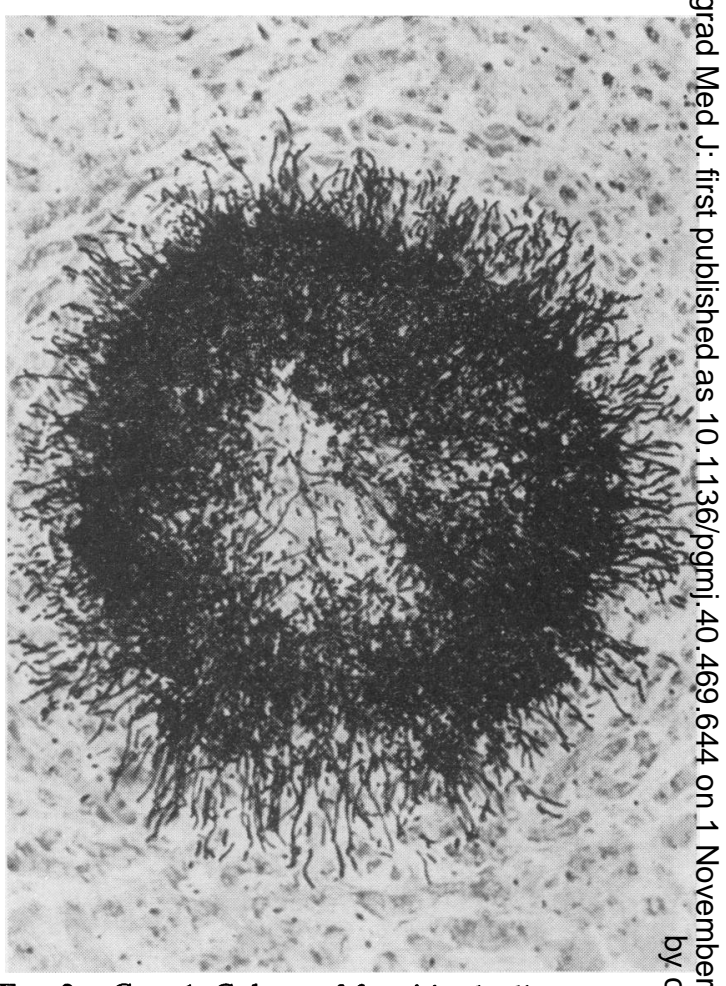

Fig. 2.-Case 1. Colony of fungi in the liver. (Hurlê, 1962).

P.A.S.H. x 135

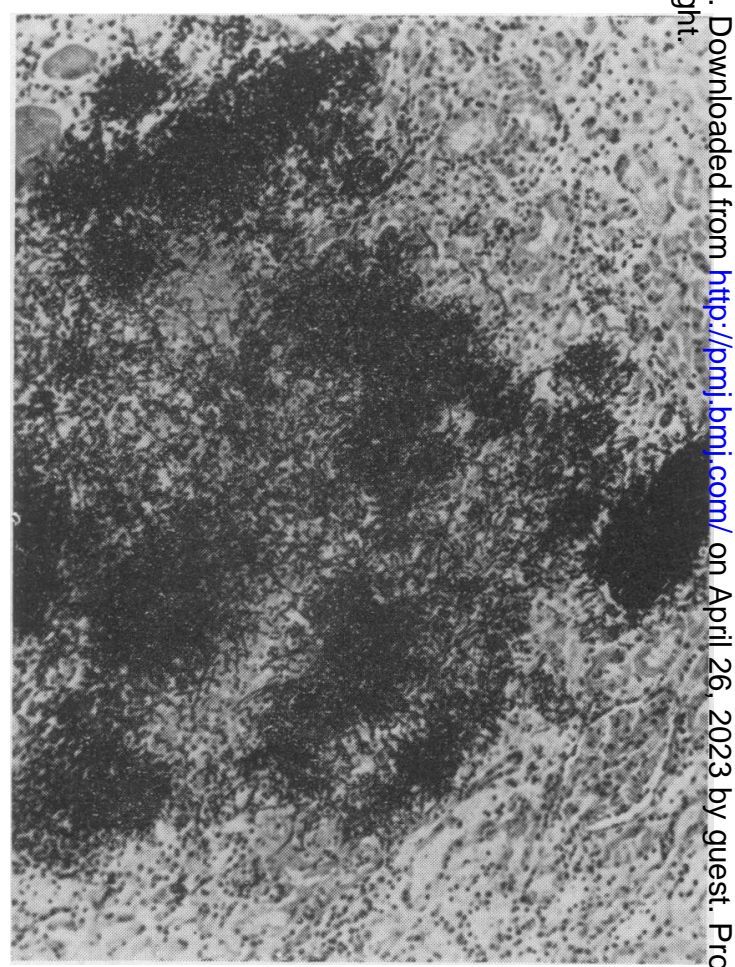

FIG. 3.-Case 1. Mycotic lesions in the kidney. There⿱ are occasional hyaline casts in the renal tubules? (Hurley, 1962).

P.A.S.H. x 80 


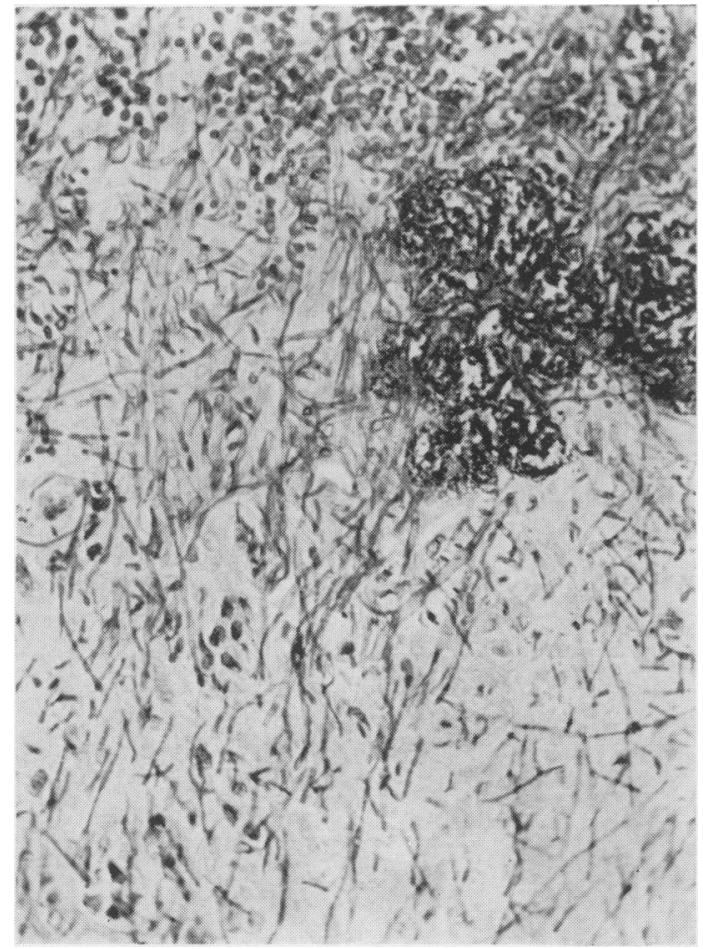

FIG. 4.-Case 2. Proliferating mycelium, yeast cells and clumps of bacteria in the wall of the oesophagus. (Hurley, 1962).

P.A.S.H. x 350

\section{Case 2.}

A female child aged six years was admitted to hospital for treatment of acute leukæmia. Temporary improvement followed treatment with prednisolone, 6-mercaptopurine and blood transfusions. After a recrudescence of the disease the dose of prednisolone was increased and the child treated with this drug until her death five months later. Five days before her death the lesions of thrush appeared in her mouth and she was febrile.

Necropsy: There was evidence of acute leukæmia. There was ulceration of both tonsils, the tongue, the soft palate and the uvula, these being covered with a white granular exudate. Similar ulceration was present in the piriform fossæ and at the tip of the epiglottis. The lower three-quarters of the œsophagus showed white confluent ulceration.

Histologically, dimorphic fungi were seen spreading into the cartilage of the larynx. There was mycotic ulceration of both tonsils, the tongue and œsophagus, focal mycotic ulceration of the intestine, a mycotic lesion of the spleen and one of the bone marrow. Proliferating strands of mycelium spread from the ulcers of the alimentary tract to invade the submucosa without evidence of reaction on the part of the tissue. In these lesions the yeastlike form tended to be superficial. Clumps of bacteria were also seen (Fig. 4); these complicated the histological picture, but made the monilial lesions more striking. Where bacteria were seen there was tissue necrosis. Immediately adjacent to this could be seen a feltwork of fungal mycelium in the vicinity of which the absence of necrosis and of inflammatory reaction was remarkable. The lesion

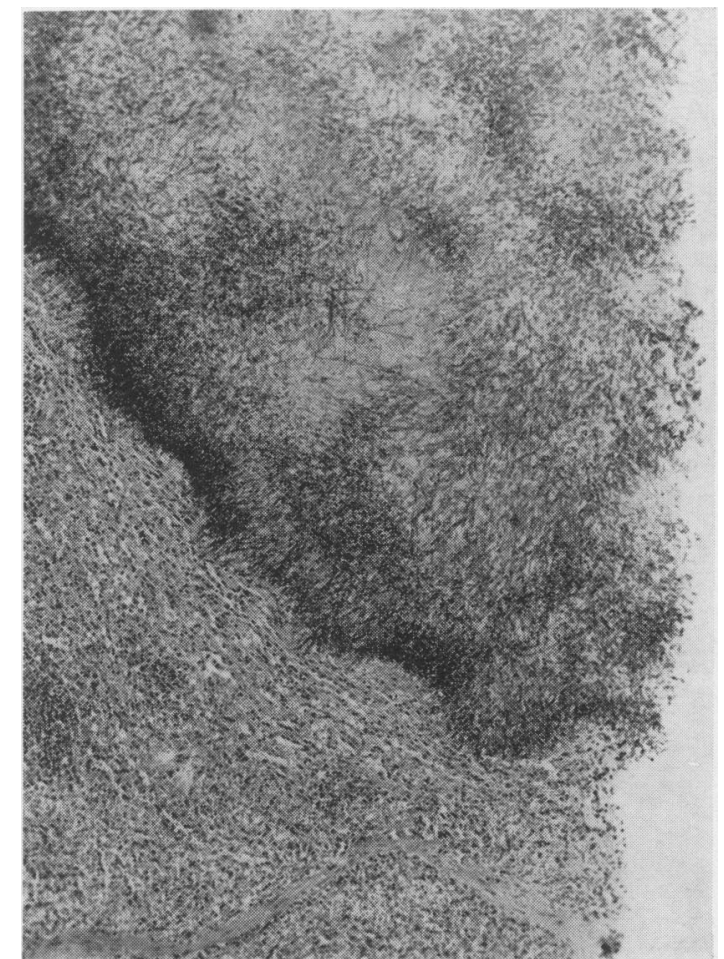

Fig. 5.- Case 2. Mycotic focus in the spleen. (Hurley, 1962).

P.A.S.H. x 50

in the spleen was rounded and peripheral and had a well-defined growing edge, composed of a fringe of mycelium. There was a suggestion of lines of pressure in the splenic pulp abutting on the fungus colony (Fig. 5).

\section{Case 3.}

A male child aged nine years was admitted to hospital for treatment of a recrudescence of acute lymphatic leukæmia which had responded previously to prednisolone and 6-mercaptopurine. The child was treated with methotrexate and transfused with whole blood. Thrombocytopenia supervened; all drugs were stopped and a platelet transfusion was given. $\mathrm{He}$ was transferred for irradiation and received 450r from a Tele-Cobalt unit; subsequently he was treated with dexamethasone, tetracycline, nystatin, potassium iodide and largactil. He was given an intravenous transfusion of bone marrow donated by his mother and his sister and he also received platelet transfusions and ACTH at this time. He developed a swinging fever of $101^{\circ} \mathrm{F}$. for which no cause was found. The white cell count continued to fall and further transfusions of whole blood and marrow were without effect. There was vomiting, and fever up to $103^{\circ} \mathrm{F}$., epistaxis and the expectoration of blood stained sputum. Blood cultures grew Staphylococcus pyogenes, and $C$. albicans was grown from the throat. He remained febrile and developed a sterile pleural effusion. He was digitalised and given prednisolone, diethazide and chloramphenicol, and a further transfusion of whole blood. Terminally there was purpura.

Necropsy: There was evidence of acute lymphatic leukæmia. The tonsils were ulcerated and there were 
DEATHS IN ENGLAND \& WALES FROM FUNGAL INFECTIONS

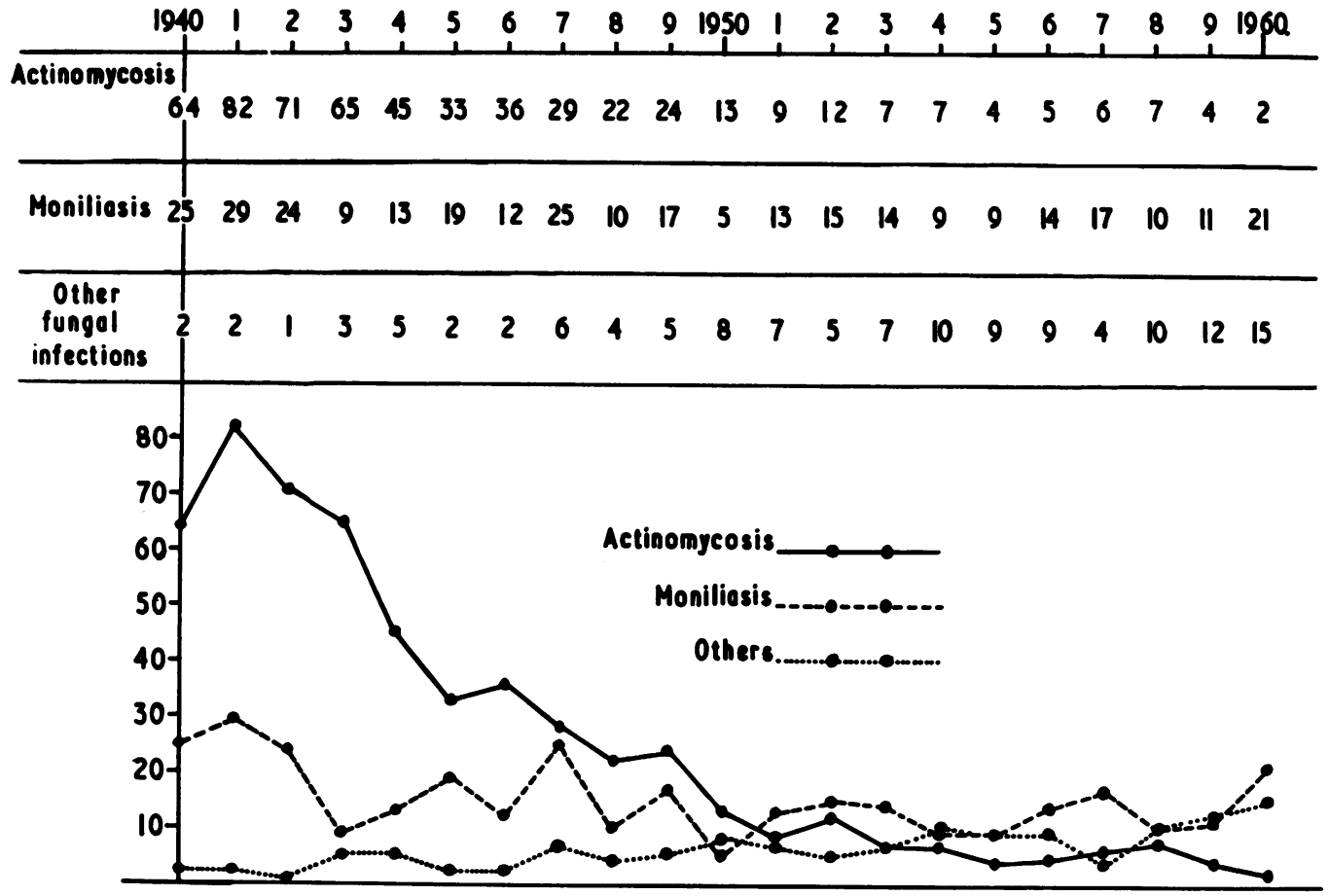

TABLE 3

ulcers on the aryepiglottic folds. The tongue was normal but there was a linear ulcer in the lower third of the œsophagus. The kidneys appeared macroscopically normal. Cultures from the lung, spleen and kidneys grew Staphylococcus pyogenes.

Histologically, there were mycotic foci in the tonsils and the csophagus and one mycotic lesion in the kidney. These were similar to those seen in Cases 1 and 2, cellular reaction being minimal and the fungus mainly in its mycelial form in the alimentary tract lesions, and the deposit in the kidney being focal and cortical.

\section{Discussion}

Despite the fact that members of the Candida genus were not cultured from the bloodstream in any of the three fatal cases reported here they are described as cases of acute disseminated (septicæmic) moniliasis since they conform olosely with previous descriptions of the disease, and histological studies showed the presence of a dimorphic fungus in the lesions. The histology of the lesions was similar to that described in other cases and in no way differed from the appearance obtaining in the experimental disease.

Increasing attention has been paid to the syndrome of disseminated moniliasis in the antibiotic era since in general it has often beer⿳亠口冋, observed to follow antibacterial antibiotie therapy. Should the relationship be causa there is reason to suppose that this serious complication might be observed with increasing frequency. The subject of increased susceptibil ity to $C$. albicans of patients treated with anti biotics is discussed by Drouhet (1957). Of the forty-eight cases of disseminated moniliasis. reviewed here, antibiotics had been given in 43. Multiple antibiotic therapy had been given to the three patients whose case reports are given. However, in the same series of cases there was always a history of underlying disease? usually serious, and invariably so in adults. In attempting to assess the clinical importance of antibiotic therapy as a precipitating of predisposing factor in systemic fungal infec tions it should be borne in mind that at the present time it is almost impossible to find a patient who has been admitted to hospital for some serious disease who has not received? antibacterial therapy. The treatment is usuallyes multiple. The observation of Robinson (1954):who showed that of 3,000 patients treated with 
oral antibiotics only two developed clinical manifestations of moniliasis, and the controversial results of experimental studies suggest that the relationship is not a direct one. The Registrar General's figures for the incidence of fatal fungus infections in England and Wales (Table 3) since 1940 also tend to confirm this view. There can be little doubt that since 1940 the administration of antibiotics has increased, but this has not been accompanied by an increase in fatal moniliasis. On the other hand, the number of deaths caused by actinomycosis, a disease amenable to antibiotic therapy, has decreased. This fact suggests that antibiotic therapy cannot be the sole factor predisposing to fatal moniliasis. Dissemination of the disease to remote viscera certainly occurred before the antibiotic era and then, as now, complicated underlying illness. So striking was the relationship between thrush and a state of lowered resistance in the host that Parrot (1877) commented that thrush was always the consequence of a previous disease and did not, of itself, constitute a malady. From the cases presented and reviewed here it would seem that the same is true to-day. However, this view does not diminish the importance of disseminated moniliasis as a complication of serious disease for which antibiotic therapy has been given. The same observations apply to steroids and other medicaments.

The relationship between disseminated moniliasis and blood dyscrasias has been recognised (Lannigan and Meywell, 1959). The relationship to surgery has been little stressed except in the case of Candida endocarditis following open heart surgery (Hyun and Collyer, 1960). The practice of whole body irradiation is likely to predispose to the disease (Case 3).

Amphotericin B. and withdrawal of other forms of treatment seem to offer the best hope of recovery (Louria and Dineen, 1960) although this treatment is not uniformly successful (Seabury and Dascomb, 1960). Recovery has followed symptomatic treatment in childhood (Vince 1959).

\section{Summary}

Forty-eight proven cases of acute disseminated (septicæmic) moniliasis are reviewed and three further presumptive cases are described. The disease is an acute, usually fatal, complication of acute or chronic debilitating illness which has been treated with multiple antibiotics, and sometimes steroids and intravenous therapy Males and females are equally affected and the disease occurs at all ages, although the prognosis is better in childhood. The presenting symptoms are those of a septicæmia with the oral or cutaneous manifestations of thrush and often a state of diminshed response to external stimuli. The disease may complicate recovery from major surgery, usually intestinal, and has been recorded after tooth extraction. The commonest group of debilitating diseases complicated by the systemic mycosis, excluding surgical conditions, is the blood dyscrasias The diagnosis is established from the clinicas state and culture of organisms of the genu? Candida from the bloodstream. Treatment is by withdrawal of antibacterial antibiotics and other medicaments and the intravenous administration of amphotericin $B$.

I am grateful to Dr. D. Dexter, Reader in Morbid Anatomy, St. George's Hospital Medical School, for permission to study and publish Cases 2 and 3 , and to Dr. G. A. Gresham, Lecturer in Pathology, University of Cambridge, for permission to study and publish Case 1, and for the post mortem report on the case by Dr. D. R. Ryrie. I thank the late Mr. K. W. Iles, Charing Cross Hospital Medical School, for the photographs, and the Registrar General for permission to publish figures pertaining to fatal fungus infections in England and Wales since 1940

\section{REFERENCES}

Andriole, V. T., Kravetz, H. M., Roberts, W. C., and Utz, J. P. (1962): Candida Endocarditis: Clinical and Pathologic Studies, Amer. J. Med., 32, 251.

Barrett, B., Volwiler, W., Kirby, W. M., and Jensen, C. R. (1957): Fatal Systemic Moniliasis following Pancreatitis. Arch. intern. med., 99, 209.

Bendel, W. L., JR., and RACE, G. J. (1961): Acute Disseminated Candidiasis in Aplastic Anemia. Potentiation by Antibiotics and Steroids, Arch. intern. Med., 108, 916.

Benham, R. W. (1931): Certain Monilias Parasitic on Man: their Identification by Morphology and by Agglutination, J. infect. Dis., 49, 183.

Berg, F. T. (1846): Om Torsk hos Barn. Stockholm: L. J. Hjerta.

BeUtHe, D. (1955): Candida Sepsis, Zbl. allg. Path. path. Anat., 93, 241.

Boyd, J. F., and Chappell, A. G. (1961): Fatal Mycetosis due to Candida albicans after Combined Steroid and Antibiotic Therapy, Lancet, ii, 19.

Braude, A. I., and Rock, J. A. (1959): The Syndrome of Acute Disseminated Moniliasis in Adults, Arch intern Med., 104, 91. 
Brown, C. JR., Propp, S., Guest, C. M., Beebe, R. T., and Early, L. (1953): Fatal Fungus Infections complicating Antibiotic Therapy, J. Amer. med. Ass., 152, 206.

Chapman, M. G. (1957): Fatal Disseminated Moniliasis during Prolonged Antibiotic Therapy, Calif. Med., 86, 120.

Conn, N. K., Crean, G. P., Maccabe, A. F., and MacLlean, N. (1959): Systemic Candidiasis and Endocarditis due to Candida tropicalis, Brit. med. J., i, 944.

ConnetT, M. C. (1960): Fatal Septic Thrombophlebitis due to Candida albicans after Prolonged Antibiotic Therapy, Arch. Surg., 81, 726.

DrouheT, E. (1957): Pathology, Diagnosis and Treatment of Moniliasis, Irish J. med. Sci., Series 6, 378, 241.

Dubos, R. J. (1958): In Bacterial and Mycotic Infections of Man, 3rd Edition, P. 592, Philadelphia: J. B. Lippincott.

Duhig, J. V., and Mead, M. (1951): Systemic Mycosis due to Monilia albicans, Med. J. Aust., 1, 179.

DuPre, J., Jones, R. V., and Penman, H. G. (1962): Candida albicans Septicæmia, Postgrad med. J., $38,176$.

FFrenCH, G., and SHENoI, V. (1954): Disseminated Moniliasis with Demonstration of the Organism in the Blood, Canad. med. Ass. J., 71, 238.

Gausewitz, P. L., JoNeS, F. S., and WORLeY, G. JR. (1951): Fatal Generalized Moniliasis: Report of a Case, Amer. J. clin. Path., 21, 41.

Hasenclever, H. F., and Mitchell, W. O. (1961): Pathogenicity of $C$. albicans and C. tropicalis, Sabouraudia, $1,16$.

Heller, A. (1895): Beitrag zur Lehre vom Soor, Dtsch. Arch. klin. Med., 55, 123.

HIGUCHI, K., and IWASAKI, H. (1958): Systemic Moniliasis complicated with Leukæmia, Kyushu J. med. Sci., 9, 139.

HuRLEY, R. (1962): The Relationship Between Host and Parasite in Systemic Moniliasis; A Clinical and Experimental Study, M.D. Thesis, Univ. Lond.

Hurley, R., and WinNer, H. I. (1962): The Pathogenicity of Candida tropicalis, J. Path. Bact., 84, 33.

HYUN, B. H., and Collier, F. C. (1960): Mycotic Endocarditis following Intracardiac Operations: A report of Four Cases, New Engl. J. Med., 263, 1339.

JoAChim, H., and PolayeS, S. H. (1940): Subacute Endocarditis and Systemic Mycosis (Monilia), J. Amer. med. Ass., 115, 205.

Lannigan, R., and Meynell, M. J. (1959): Moniliasis in Acute Leukæmia, J. clin. Path., 12, 157.

LEHNER, T. (1964): Systemic Candidiasis and Renal Involvement, Lancet, i, 1414.

Lelong, M., Alison, F., Tan Vinh., Van Ty, D., Desmonts, G., and CanAbes, J. (1953): Le Maguet Généraliség (Septicémie à Candida albicans). Ann. Méd., 54, 5.

Levy, E. S., and CoHEN, D. B. (1955): Systemic Moniliasis and Aspergillosis complicating Corticotropin Therapy? Arch. intern. Med., 95, 118.

LewIN, K. (1963): Two Cases of Monilial Septicæmia, Secondary to Carcinoma of the Mouth successfully treated with Amphotericin B., Postgrad. med. J., 39, 359.

Louria, D. B. (1962): Disseminated Moniliasis in the Adult, Medicine, 414, 307.

LOURIA, D. B., and DineEN, P. (1960): Amphotericin B. in Treatment of Disseminated Moniliasis, J. Amer. med. Ass., 174, 273.

LudLAM, G. B., and Henderson, J. L. (1942): Neonatal Thrush in a Maternity Hospital, Lancet, i, 64.

MACKINNON, J. E. (1936): Caracteres y Grado de la Virulencia Experimental de las Torulopsidáceas de la Subfamilia Mictorulaceas (Monilias), An. Fac. Med. Montevideo, 21, 320.

Mankowski, Z. T. (1957): The Experimental Pathogenicity of Various Species of Candida in Swiss Mice, Trans. N.Y. Acad. Sci., 19, 548.

Matthias, J. Q., and Rees, E. G. (1956): Candida Septicæmia Complicating Antibiotic Therapy, J. Path. Bact. 71, 512.

Meyer, E., and Ordal, Z. J. (1946): Pathogenicity of Candida Species for the Chick Embryo, J. Bact., 52, 615.

Parillo, O. J. (1950): Disseminated Mycotic Disease: Report of Three Cases, J. Amer. med. Ass., $144,747$.

Parrot, J. M. J. (1877): Clinique des Nouveau-Nés. L'athrepsie. Leçons Recuelliés par le Dr. Troisier. Paris: G. Masson.

Pearl, M. A., and Sidransky, H. (1960): Candida Endocarditis: Two New Cases with a review of 12 Previously Reported Cases, Amer. Heart. J., 60, 345.

Plaut, H. C., and Grütz, O. (1928): Die Hyphenpilze oder Eumyceten. In Handbuch der pathogenen Mikroorganismen; 3rd Edition. W. Kolle, R. Kraus and P. Uhlenhuth. Volume 5, 133-320. Jena: G. Fischer.

Polayes, S. H., and Emmons, C. W. (1941): Final Report on the Identification of the Organism of the Previously Reported Case of Subacute Endocarditis and Systemic Mycosis (Monilia), J. Amer. med. Ass. $117,1533$.

Richart, R., and Dammin, G. J. (1960): Candida tropicalis as a Pathogen for Man, New Engl. J. Med., 263, 474.

Richet, G., Drouhet, E., Ducror, H., and Jungers, P. (1959): Guérison de Deux Cas de Septicémie à Candida albicans Compliquant une Anurie Grave. Action de l'amphotéricine B., Bull. Soc. méd. Hôp., Paris, 75, 780.

Robertson, J. A. (1956): Systemic Moniliasis. Report of a Case. Calif. Med., 84, 115.

Robinson, H. M. JR. (1954): Moniliasis Complicating Antibiotic Therapy: Clinical and Laboratory Studies. A.M.A. Arch. Derm. Syph., 70, 640.

SABesin, S. M. (1962): Renal Failure and Disseminated Candidiasis, Arch. intern. Med., 110, 526.

Schaberg, A., Hildes, J. A., and Wilt, J. C. (1955): Disseminated Candidiasis, Arch. intern. Med., 95, 112.

SeabuRY, J. H., and DascomB, H. E. (1958): Experience with Amphotericin B for the Treatment of Systemic Mycoses, Arch. intern. Med., 102, 960. 
Skobel, P., JoRke, D., and SChABINSKI, G. (1955): Akute Generalisierte Mykose: Sepsis durch Candida pseudotropicalis, Münch, Med. Wschr., 97, 194.

Stein, A. A. (1959): Systemic Moniliasis: A Clinicopathological Report of Five Cases, Antibiot. Med., 6, 297.

Van Buren, J. M. (1958): Septic Retinitis due to Candida albicans, Arch. Path., 65, 137.

VINCE, S. (1959): The Spread of Candida in Infants and Children, Med. J. Aust., 46, 143.

WAGNER, E. (1868): Zur Kenntnis des Soors des Oesophagus, Jb. Kinderheilk., 1, 58.

Walz, D. V., Hasenclever, H. F., and McKee, A. P. (1956): A Dual Human Infection with Candida albicans and Cryptococcus neoformans, Amer. J. clin. Path., 26, 794.

WeGMANN, T. (1954): Pilzerkrankungen der Inneren Organe als Folge von Behandlung mit Antibiotica, unter Besonderer Berücksichtigung des Respirationstraktes, Antibiot. et Chemother., 1, 235.

WeSSLER, S., and BRowne, H. R. (1945): Candida albicans (Monilia albicans) Infection with Blood Stream Invasion. Report of a Case with a Strain Clinically Resistant to Sulfonamide Drugs and to Penicillin in vitro, Ann. intern. Med., 22, 886.

WinNER, H. I., and HURLEY Rosalinde (1964): Candida Albicans. London: J. \& A. Churchill.

ZeNKER, W. (1861-1862): Encephalitis mit Pilzentwicklung im Gehirn, Jb. Ges. Natur. u. Heilk. (Dresden), 51. 